\title{
BIM NO ENSINO DAS COMPETÊNCIAS EM ARQUITETURA E URBANISMO: TRANSFORMAÇÃO CURRICULAR
}

\section{BIM IN THE TEACHING OF COMPETENCIES IN ARCHITECTURE AND URBANISM: CURRICULAR TRANSFORMATION}

\author{
Paula Batistello ${ }^{1}$ \\ Universidade Comunitária da Região de Chapecó - Unochapecó, Chapecó, SC, Brasil, paula.batistello@unochapeco.abea.arq.br \\ Katiane Laura Balzan ${ }^{2}$ \\ Universidade Comunitária da Região de Chapecó - Unochapecó, Chapecó, SC, Brasil, katilaura@unochapeco.edu.br
}

Alice Theresinha Cybis Pereira ${ }^{3}$

Universidade Federal de Santa Catarina -UFSC, Florianópolis, SC, Brasil, acybis@gmail.com

\begin{abstract}
Resumo
O sistema de ensino tradicional, apresentado de forma expositiva e com o professor sendo a fonte das informações, vem sendo substituído em muitas instituições de ensino no mundo há algum tempo. Métodos envolventes e a constante formatação de novas salas de aula e intervenções para a aprendizagem buscam a apreensão das habilidades e competências profissionais nos acadêmicos dos cursos de Arquitetura e Urbanismo. O ensino baseado em competências abrange conhecimentos, habilidades e atitudes, ou seja, teoria, saber fazer e a aplicação prática. Este artigo visa evidenciar como a metodologia BIM apoia a integração dos conhecimentos inerentes ao processo projetual, reforçando a aprendizagem baseada em competências, para a formação do futuro profissional. Esta pesquisa foi realizada como um estudo teórico sobre o processo e métodos de projetos, contextualizando autores historicamente e, a partir da síntese deste referencial, foram relacionadas as competências à aplicação do BIM no processo de aprendizagem em um curso de Arquitetura e Urbanismo. Os resultados apontam a tecnologia BIM como uma metodologia importante e diferenciada para articular as competências, destacando a interdisciplinaridade nas soluções projetuais. Este trabalho poderá contribuir com a discussão da inserção desta tecnologia em outros cursos de diferentes Instituições de Ensino.
\end{abstract}

Palavras-chave: Métodos de projeto. Aprendizagem baseada em competências. Metodologia BIM.

\begin{abstract}
The traditional teaching system, presented in an expositive manner and with the teacher being the source of information, has been replaced in many educational institutions in the world for some time. Involving methods and the constant formatting of new classrooms and interventions for learning, seek the apprehension of professional skills and competencies in the academics of the Architecture and Urbanism courses. Competency-based education encompasses knowledge, skills and attitudes, that is, theory, knowhow and the practical application. This paper aims to highlight how the BIM methodology supports the integration of knowledge inherent to the design process, reinforcing competency-based learning for future professional formation. This research was carried out as a theoretical study about the process and methods of projects, contextualizing authors historically and, from the synthesis of this referential, were related the competences to the application of BIM in the learning process in the course of Architecture and Urbanism. The results point to BIM technology as an essential and differentiated methodology for articulating skills and competencies, highlighting interdisciplinarity in design solutions. This work may contribute to technology in other courses of different Teaching Institutions..
\end{abstract}

Keywords: Design methods. Competency-based learning. BIM methodology.

How to cite this article:

BATISTELLO, Paula; BALZAN, Katiane Laura; PEREIRA, Alice Theresinha Cybis. BIM no ensino das competências em arquitetura e urbanismo: transformação curricular. PARC Pesquisa em Arquitetura e Construção, Campinas, SP, v. 10, p. e019019, abr. 2019. ISSN 1980-6809. Disponível em: https://periodicos.sbu.unicamp.br/ojs/index.php/parc/article/view/8653989. Acesso em: 27 abr. 2019. doi:https://doi.org/10.20396/parc.v10i0.8653989. 


\section{Introdução}

O aprendizado da profissão de arquiteto e urbanista envolve uma série de precedentes e bases de escolas internacionais, com metodologias e valorizações de conhecimentos distintos que influenciaram a formação do currículo brasileiro. O início do exercício profissional na construção civil se deu a partir da matriz portuguesa, com a vinda dos descobridores e a ocupação do solo brasileiro. A primeira regulamentação se deu pelo decreto $n^{\circ} 23.569$ de 1933 , que regulava as profissões de Engenheiro, Arquiteto e Agrimensor, seguida da Lei 5.194/1966, que regulava as profissões de Engenheiro, Arquiteto e Engenheiro-Agrônomo e, finalmente, regulada pela Lei 12.378/2010 (BRASIL, 2010a), com a criação de um conselho próprio chamado Conselho de Arquitetura e Urbanismo (CAU) (INEP e CONFEA, 2010).

Para compreender as competências e habilidades exigidas dos profissionais de Arquitetura e Urbanismo, assim como as matrizes curriculares atuais que embasam esses conhecimentos e fornecem as habilidades, é necessário compreender as influências da formação desta escola no Brasil. O esquema apresentado na Figura 1, baseado em INEP e CONFEA (2010), aponta as fortes tendências da formação profissional com base na arquitetura militar e influências da escola portuguesa mais voltada à engenharia e, posteriormente, das Belas Artes - com influência francesa - o que fez a atuação voltar o foco ao projeto e não à execução.

Atualmente, preconiza-se a formação de um profissional generalista ${ }^{(1)}$. As atribuições e os conteúdos mínimos para a formação do arquiteto e urbanista são definidos pelas Diretrizes Curriculares Nacionais (DCNs) (BRASIL, 2010b) e pela Lei 12378/2010 (BRASIL, 2010a), que regulamenta o exercício da Arquitetura e Urbanismo no Brasil. A formação generalista é tratada curricularmente através de matrizes compostas por várias disciplinas, fruto de tantas influências entre o que o arquiteto e urbanista deve ou não saber, considerando o predomínio do conhecimento de construção civil ou do artístico, bem como de uma formação de ciências exatas ou sociais, os currículos acabam sendo amplos e pouco integrados.

Com esse histórico, os saberes inerentes ao conhecimento da profissão de arquiteto e urbanista foram se tornando cada vez mais amplos e ao mesmo tempo isolados nas linhas de conhecimento, sem dar a atenção devida ao momento em que o profissional deve mostrar suas habilidades a partir das ações que aplicam esses conhecimentos.

Segundo Lee, Sacks e Eastman (2006), Building Information Modeling (BIM) deve auxiliar no processo de criação e gerenciamento de informações dos projetos, respectiva execução da obra e operação da edificação, com integração de conhecimentos, de forma que resulte em um modelo digital do edifício ao invés de uma série de desenhos, o que permite modificações de modo fácil e intuitivo. Como os desenhos são gerados de um modelo, este deve ser o mais completo possível e apresentar alto nível de compatibilização entre as disciplinas (projeto arquitetônico, estrutural e de instalações). Desta maneira, em uma aprendizagem integrada, as competências serão alcançadas. 
BAtISTEllo, Paula; BALZAN, Katiane Laura; PEREIRA, Alice Theresinha Cybis.

BIM no ensino das competências em arquitetura e urbanismo: transformação curricular

Figura 1 - Linha do tempo das influências do ensino de Arquitetura e Urbanismo no Brasil baseada em INEP e CONFEA (2010)

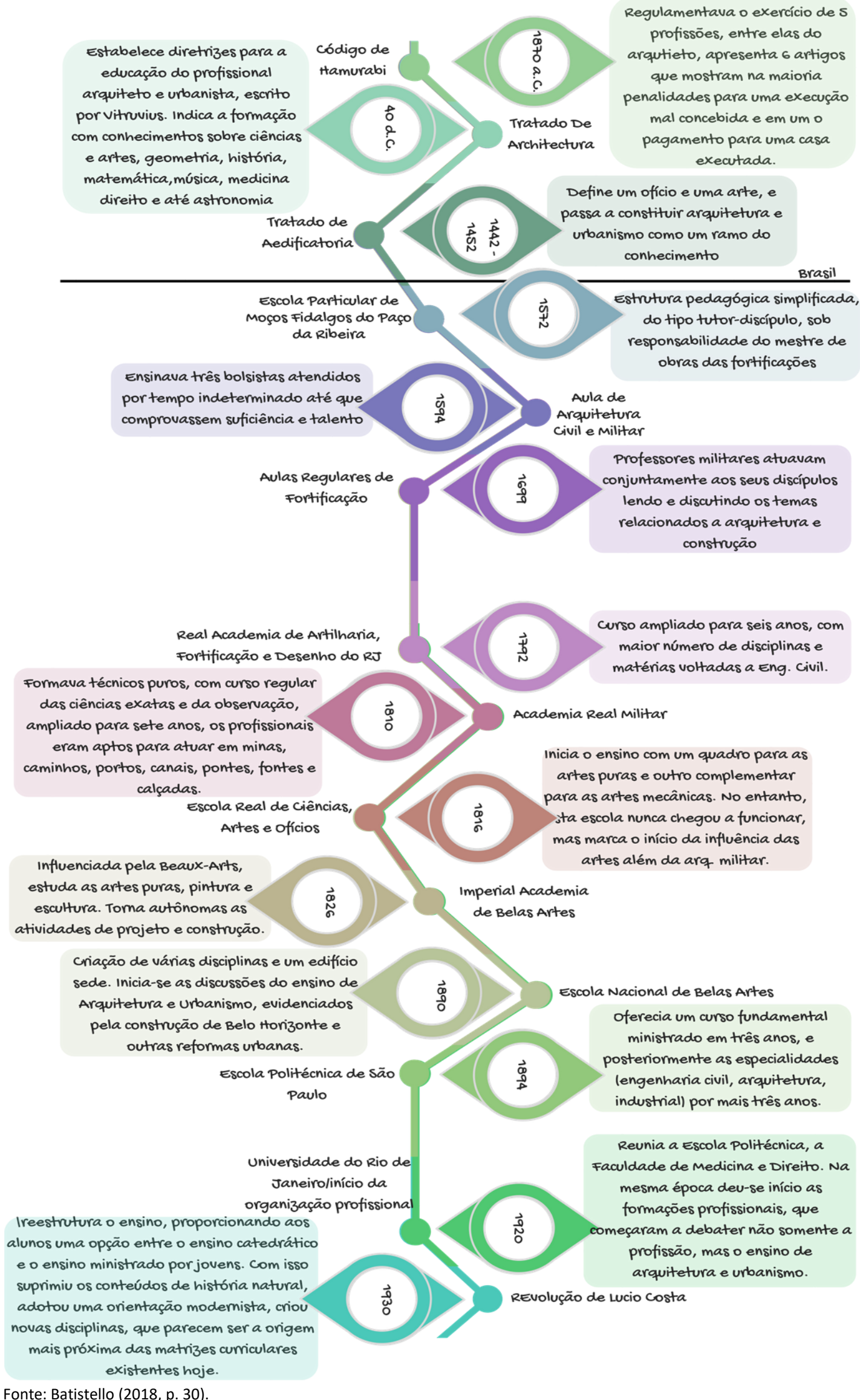


Corroborando, Van der Klink, Boon e Schlusmans (2007), afirmam que uma variante do ensino baseado em competências é uma abordagem integrada que dá atenção tanto à renovação didática como à otimização da relação com o mercado de trabalho. Ainda, Van der Klink e Boon (2003) mostram que as competências abrangem: conhecimentos, habilidades e atitudes; também conhecidas no mundo da gestão, como tríade de competências. Neste contexto é possível entender: o conhecimento como a teoria; as habilidades como o saber fazer; e as atitudes como a ação de colocar em prática. Em síntese atitudes sem conhecimentos não geram resultados, por isso as atitudes devem ser respaldadas na integração de conhecimentos.

Para compreender o processo da aprendizagem projetual, explicar-se-á um pouco do processo de projeto e das competências inerentes ao aprendizado do arquiteto e urbanista.

\section{As competências profissionais em arquitetura e urbanismo}

As competências exigidas para a formação em arquitetura e urbanismo agregam conhecimentos antropológicos, sociais, econômicos, ambientais, artísticos, construtivos, tecnológicos, estruturais, gráficos, entre outros. Para serem efetivos nas áreas de atuação projetuais, os acadêmicos e futuros profissionais precisam dominar as habilidades para adentrarem ao mercado de trabalho com o perfil generalista almejado pelas DCNs.

À fim de atender a este perfil, as DCNs e a Lei 12378/2010 atribuem, aos currículos escolares e às atividades profissionais, várias habilidades e competências, apresentadas no Quadro 1, a partir de suas bases de conhecimento.

Quadro 1 - Relação complementar de conhecimentos desejados ao arquiteto e urbanista pelas diretrizes curriculares nacionais e pela Lei $12378 / 2010$

\begin{tabular}{|c|c|}
\hline DCN'S 02/2010 & Lei 12378/2010 \\
\hline Projeto de arquitetura & Projeto de arquitetura \\
\hline Projeto de paisagismo & Projeto de urbanismo \\
\hline Projeto de urbanismo & Projeto de interiores \\
\hline Desenho e meios de representação gráfica & \\
\hline Estética e história das artes & \\
\hline Estudos sociais e econômicos & \\
\hline Estudos ambientais & Meio ambiente, estudo de avaliação dos impactos ambientais \\
\hline Teoria e história da arquitetura, do urbanismo e do paisagismo & Topografia e interpretação de levantamentos topográficos \\
\hline Topografia & Tecnologia e resistência dos materiais \\
\hline Sécnicas retrospectivas & Projeto do patrimônio histórico, cultural e artístico \\
\hline Estágio supervisionado & \\
\hline
\end{tabular}

Fonte: BRASIL, Lei 12378/2010, E BRASIL, Res. no 2/2010, interpretado pelas autoras

É importante ressaltar que os conhecimentos os quais os profissionais devem dominar para a execução de suas tarefas e a relação destes conhecimentos com as habilidades, que criam as competências.

Para que a relação do ensino baseado em competências seja eficiente, é necessário que uma mesma habilidade seja capacitada por conhecimentos distintos. No entanto, especialmente pelo resultado do formato curricular baseado em disciplinas, que hoje é corrente no País, muitas habilidades são tratadas individualmente, sem fortalecer o sentido de capacitar o perfil generalista do profissional.

Segundo Cotta, Costa e Mendonça (2013), para um aprendizado autônomo no qual o ponto central da formação não seja mais o ensino, mas sim a aprendizagem, é necessário ter uma implementação de estratégias pedagógicas mais ativas e 
inovadoras, com instrumentos que permitam alcançar competências importantes para o exercício acadêmico e profissional. O projeto apreendido em ateliê, utilizando a prática de projetar, desenhando, modelando, simulando, é uma estratégia ativa, no entanto, se não houver a integração dos conhecimentos ao decorrer do processo e esses instrumentos não forem aplicados, a prática pode se tornar pouco experimental e muitas vezes sem sentido.

Entende-se que algumas ferramentas podem ajudar na compreensão do processo projetivo e a tecnologia BIM é uma delas. Desta forma, para compreender onde a tecnologia BIM pode atuar na inovação da aprendizagem estimulando a formação das competências, compreender-se-á a seguir como funciona o processo de projeto.

O processo de projeto

Os processos e métodos de projetos aplicados atualmente na maioria das escolas de Arquitetura e Urbanismo brasileiras, são advindos das estruturas curriculares que distribuem conteúdos em disciplinas. Lawson (2011) faz uma crítica ao método de ensino de projeto - o ateliê físico e conceitual como principal mecanismo de ensino. Neste método, segundo o autor, o processo de aprender é "fazendo", onde a ênfase maior é direcionada ao produto final e deixam de refletir sobre o processo de projeto. Lawson (2011) atenta ainda, que a solução deve ser concebida pelo processo de projeto e não pelo produto pretendido. É sobre o processo que é preciso discutir.

O processo de aprender "fazendo", não é o mesmo processo de "saber fazer", que trabalha as habilidades acadêmicas. O diferencial para o saber fazer, é trabalhar as habilidades a partir dos conhecimentos prévios, que pode ser adquirido pela problematização e construção do conhecimento, e aqueles que durante o processo de aprendizado serão adquiridos.

As discussões sobre métodos e processos de projeto iniciaram com projetistas retratando o progresso das atividades do início à solução final. Definir métodos era necessário para minimizar custos na execução dos projetos, uma consequência da diminuição de erros. Assim, o processo de projeto foi retratado como a sequência íntegra de acontecimentos, que parte de suas primeiras concepções e vai até a sua realização total, onde a sequência de decisões é um intervalo individual do processo de projeto, seja a captação de informação, a análise, a síntese, etc.

Asimow (1968) diz que o processo de projeto descreve a reunião, manuseio e organização criadora de informações relevantes ao problema, prescreve a derivação de decisões, que são otimizadas, comunicadas e testadas ou avaliadas, com um caráter iterativo, pois enquanto surgem novas informações, novas interpretações são feitas e as operações devem ser repetidas. Desta forma, o autor suscinta o processo de projeto em: análise, síntese, avaliação e decisão; e o estende aos domínios da otimização, revisão e execução.

Broadbent (1971) expõe que o processo de projeto é a sequência íntegra de acontecimentos desde a primeira concepção até a realização total do projeto; e que as informações, análises e sínteses são intervalos individuais do processo, denominados como sequência de decisões. Diferentemente de Markus (1971), para Broadbent (1971) não há um processo cíclico no projeto, a sequência é única, do início até o seu final.

Para Jones (1976) os princípios de criação de projetos estão relacionados com a caixa preta ou a caixa transparente. Na caixa preta, a saída de dados é comandada pela entrada recente dos mesmos e pode ser acelerada mediante a suavização das inibições 
anteriores. Já na caixa transparente, ainda sob a avaliação de Jones (1976), o processo é claro e supõem-se que há uma consciência completa das decisões projetuais, onde a resposta seria mais assertiva. Entretanto, a intuição pode ser desperdiçada e as soluções menos criativas.

Segundo Andrade, Ruschel e Moreira (2011) os métodos de projeto indicados por Jones (1976), Markus (1971), Broadbent (1971), Asimow (1968) e atualmente indicado por Lawson (2011), apesar de serem estruturados com formas ou nomenclaturas diferenciadas tendem sempre a três fases essenciais de métodos projetuais: análise, síntese e avaliação. Porém, vale lembrar que Lawson (2011) sintetiza o processo de projeto sem uma sequência de atividades, diferente de todos os outros autores citados anteriormente. $O$ autor conclui que é preciso haver um resumo do problema onde o projetista estuda e entende as exigências, produz uma ou mais soluções, testaas em relação a critérios explícitos ou implícitos e transmite o projeto a clientes e construtores. Esse método é mais iterativo, realimentado e a partir dele é possível pensar em um processo de projeto mais atual, onde o BIM toma forças a partir das possíveis simulações.

Eastman et al. (2014) abordam pontos de vista do processo de projeto a partir da aplicação do BIM: i) o processo conceitual, onde a criação do projeto é concebida e determina as próximas etapas que envolverão o todo, contemplando volumetria, condicionantes ambientais, impactos do sítio, entre outros; ii) a análise dos sistemas de construção, simulando e avaliando as decisões e refletindo sobre elas com parâmetros aplicáveis ao edifício real; e iii) geração de informações, que são os variados documentos gerados pela ferramenta BIM.

Segundo Campos Netto (2016), um dos benefícios de projetar virtualmente em 3D utilizando as ferramentas BIM é verificar interferências entre as várias disciplinas atuantes na construção, o que ajuda a reforçar as competências, a partir de várias habilidades trabalhadas em um só projeto.

Desta maneira, o processo básico apresentado anteriormente, com um caráter histórico, demonstra o início de uma nova era de práticas projetuais, que facilita a retroalimentação de informações a vários profissionais de forma inter e multidisciplinar, já que a cada sequência de decisão - considerando a terminologia de Markus (1971) - é possível simular, averiguar, refletir e tomar novas decisões.

Quando se abre possibilidades para o acadêmico explorar seus conhecimentos prévios e de pesquisas, para fazer experimentações e simulações durante o processo projetual, então a avaliação pode ser realizada durante o processo de síntese, ou até de análise, em partes e gradativamente, conforme se estrutura o projeto.

\section{BIM como ferramenta de aprendizagem}

Para compreensão do objetivo deste artigo, é necessário compreender que a tecnologia BIM não é somente uma ferramenta de aprendizagem, mas influencia o processo de projeto, e especialmente, possibilita a interdisciplinaridade potencializando a formação baseada em competências.

Conforme apresentado por Azhar, Khalfan e Maqsood (2012), o BIM aborda dois pontos de vista: da tecnologia, como simulador de projetos; e como processo, envolvendo conhecimentos e sistemas em um único modelo virtual, o qual possibilita a integração e a colaboração entre equipes. Corroborando, Delatorre (2014) afirma que os pilares do BIM são a comunicação e a colaboração, sendo que o sucesso da aplicação depende do envolvimento dos profissionais já nas fases iniciais do projeto, diferindo do processo tradicional. 
Ratificando o perfil generalista desejado, o coordenador e os atuantes no processo necessitam ter conhecimentos gerais e inerentes à profissão do arquiteto e urbanista para o bom andamento de projetos em BIM.

No processo de projeto tradicional e ainda muito aplicado, muitas vezes, os profissionais atuam nas fases projetuais de análise, síntese e avaliação isoladamente, integrando os demais conhecimentos posteriormente, após a efetivação das soluções arquitetônicas. Nesta prática, os projetos são encaminhados finalizados para que os projetos complementares sejam realizados, a partir de um bem estruturado, já discutido e definido com os clientes, muitas vezes sem possibilidades de evolução.

Delatorre (2014) apresenta grandes potencialidades do BIM na aplicação da aprendizagem:
a) Contribuição para casos reais;
b) Ensino combinado de diferentes métodos de integração para o projeto;
c) Informações de planejamento, incorporação de tarefas de gerenciamento com atribuições a diferentes pessoas;
d) Otimização do plano de projeto;
e) Melhoria na análise, na validação e na verificação;
f) Diminuição de erros pela integração de disciplinas;
g) Redução do número de erros de projeto;
h) Estímulo ao uso de análises e simulações durante as fases projetuais que contemplam custos, conforto térmico, acústico e lumínico;
i) Coordenação eficaz entre o projeto arquitetônico e os de conhecimentos inerentes;
j) Melhoria e maior rapidez na tomada das decisões.

Segundo Checcucci (2014), a integração de diferentes conteúdos e disciplinas, e a necessidade de colaboração dos diversos professores são duas das grandes dificuldades a serem superadas para adotar o BIM nos processos de aprendizagem. É necessário refletir no processo de aprendizagem com a ideia da formação das competências, onde a interdisciplinaridade é fundamental para o exercício das mesmas.

$\mathrm{Na}$ academia brasileira, há ainda poucos trabalhos de equipes multidisciplinares, ou a partir de cursos afins, o que talvez seja a tarefa mais difícil e de maior resistência de implementação da tecnologia BIM. Ruschel, Andrade e Morais (2013), trazem algumas experiências sobre o ensino da tecnologia BIM no Brasil e mostram que algumas escolas já a aplicam, variando os níveis de competência entre introdutório e intermediário, no entanto, nenhuma delas envolvendo o nível avançado onde há colaboração de múltiplos agentes e criação compartilhada. A interdisciplinaridade faz parte do conhecimento do arquiteto e urbanista, ou seja, a aplicação de diferentes conhecimentos em um só projeto. É especialmente neste sentido que a tecnologia BIM pode auxiliar.

\section{Objetivo}

A partir do exposto, o objetivo deste artigo é apresentar como a tecnologia BIM pode ser facilitadora nos processos de aprendizagem de projeto, potencializando a formação baseada em competências e interdisciplinar.

\section{Método}

A pesquisa apresentada neste artigo foi executada a partir de um método exploratório, com discussão teórica aliada a experimento didático. Consultou-se literatura e legislação especializadas para embasar os conceitos de processo de projeto, BIM e a compreensão das competências e conhecimentos destinados à formação do profissional arquiteto e 
urbanista. O experimento didático trata do conhecimento da aplicação da tecnologia BIM, por parte das autoras, em matriz corrente de um curso de arquitetura e urbanismo da Universidade Comunitária da Região de Chapecó (UNOCHAPECÓ), que optou por assumir a integralização desta inserindo o BIM como metodologia e ferramenta de projeto, desde o primeiro semestre do curso. Desta forma, o experimento didático é reportado aliado ao conhecimento teórico e relacionado às legislações vigentes que preconizam as competências do estudante e profissional da Arquitetura e Urbanismo.

\section{Relacionando competências e o BIM}

Refletindo sobre os conceitos relacionados anteriormente, fica clara a necessidade da interdisciplinaridade nos cursos de arquitetura e urbanismo, voltados a efetivação de competências para o futuro profissional. Desta forma, visando esclarecer todas as suas relações, elencar-se-á a seguir, a partir das competências desejadas, os conhecimentos que podem ser trabalhados a partir da ferramenta BIM para fortalecer a integração de conteúdos e efetivar as habilidades profissionais. No Quadro 2 é possível averiguar essa relação.

Quadro 2 - Relação de conteúdos que podem ser integrados com a ferramenta BIM e a competência que podem fortalecer

(continua)

\begin{tabular}{|c|c|}
\hline Competências & $\begin{array}{l}\text { Conteúdos que podem ser efetivados com o apoio } \\
\qquad \text { do BIM }\end{array}$ \\
\hline \multicolumn{2}{|l|}{$\begin{array}{l}\text { Conhecimento dos aspectos antropológicos, sociológicos e econômicos } \\
\text { relevantes e de todo o espectro de necessidades, aspirações e expectativas } \\
\text { individuais e coletivas quanto ao ambiente construído }\end{array}$} \\
\hline $\begin{array}{l}\text { Compreensão das questões que informam as ações de preservação da } \\
\text { paisagem e de avaliação dos impactos no meio ambiente, com vistas ao } \\
\text { equilíbrio ecológico e ao desenvolvimento sustentável }\end{array}$ & $\begin{array}{l}\text { Estudos ambientais, conforto ambiental e } \\
\text { topografia }\end{array}$ \\
\hline $\begin{array}{l}\text { Habilidades necessárias para conceber projetos de arquitetura, urbanismo e } \\
\text { paisagismo, e para realizar construções, considerando os fatores de custo, } \\
\text { de durabilidade, de manutenção e de especificações, bem como os } \\
\text { regulamentos legais, de modo a satisfazer as exigências culturais, } \\
\text { econômicas, estéticas, técnicas, ambientais e de acessibilidade dos usuários }\end{array}$ & $\begin{array}{l}\text { Projeto de arquitetura, projeto de paisagismo, } \\
\text { projeto de urbanismo e projeto de interiores }\end{array}$ \\
\hline \multicolumn{2}{|l|}{$\begin{array}{c}\text { Conhecimento da história das artes e de estética, suscetível de influenciar a } \\
\text { qualidade da concepção e da prática da arquitetura, urbanismo e } \\
\text { paisagismo }\end{array}$} \\
\hline \multicolumn{2}{|l|}{$\begin{array}{l}\text { Conhecimentos de teoria e de história da arquitetura, do urbanismo e do } \\
\text { paisagismo, considerando sua produção no contexto social, cultural, político } \\
\text { e econômico tendo como objetivo a reflexão crítica e a pesquisa }\end{array}$} \\
\hline $\begin{array}{c}\text { Domínio de técnicas e metodologias de pesquisa em planejamento urbano e } \\
\text { regional, urbanismo e desenho urbano, bem como a compreensão dos } \\
\text { sistemas de infraestrutura e de trânsito, necessários para a concepção de } \\
\text { estudos, análises e planos de intervenção no espaço urbano, metropolitano } \\
\text { e regional }\end{array}$ & $\begin{array}{l}\text { Projeto de paisagismo, projeto de urbanismo e } \\
\text { planejamento urbano e regional }\end{array}$ \\
\hline $\begin{array}{l}\text { Conhecimentos especializados para o emprego adequado e econômico dos } \\
\text { materiais de construção e das técnicas e sistemas construtivos, para a } \\
\text { definição de instalações e equipamentos prediais, para a organização de } \\
\text { obras e canteiros e para a implantação da infraestrutura urbana }\end{array}$ & $\begin{array}{l}\text { Projeto de arquitetura, projeto de paisagismo, } \\
\text { sistemas estruturais, tecnologia da construção e } \\
\text { planejamento urbano e regional }\end{array}$ \\
\hline $\begin{array}{l}\text { Compreensão dos sistemas estruturais e o domínio da concepção e do } \\
\text { projeto estrutural, tendo por fundamento os estudos de resistência dos } \\
\text { materiais, estabilidade das construções e fundações }\end{array}$ & $\begin{array}{l}\text { Projeto de arquitetura, sistemas estruturais e } \\
\text { tecnologia da construção }\end{array}$ \\
\hline $\begin{array}{l}\text { Entendimento das condições climáticas, acústicas, lumínicas e energéticas e } \\
\text { o domínio das técnicas apropriadas a elas associadas }\end{array}$ & Projeto de arquitetura e conforto ambiental \\
\hline $\begin{array}{c}\text { Práticas projetuais e as soluções tecnológicas para a preservação, } \\
\text { conservação, restauração, reconstrução, reabilitação e reutilização das } \\
\text { edificações, conjuntos e cidades }\end{array}$ & Projeto de arquitetura e técnicas retrospectivas \\
\hline
\end{tabular}




\begin{tabular}{|c|c|}
\hline Competências & $\begin{array}{l}\text { Conteúdos que podem ser efetivados com o apoio } \\
\text { do BIM }\end{array}$ \\
\hline $\begin{array}{l}\text { As habilidades de desenho e o domínio da geometria, de suas aplicações e } \\
\text { de outros meios de expressão e representação, tais como perspectiva, } \\
\text { modelagem, maquetes, modelos e imagens virtuais }\end{array}$ & $\begin{array}{l}\text { Projeto de arquitetura, projeto de paisagismo, } \\
\text { projeto de urbanismo, projeto de interiores, } \\
\text { desenho e meios de representação gráfica e } \\
\text { informática aplicada à arquitetura e urbanismo }\end{array}$ \\
\hline $\begin{array}{l}\text { O conhecimento dos instrumentais de informática para tratamento de } \\
\text { informações e representação aplicada à arquitetura, ao urbanismo, ao } \\
\text { paisagismo e ao planejamento urbano e regional }\end{array}$ & $\begin{array}{l}\text { Projeto de arquitetura, projeto de paisagismo, } \\
\text { projeto de urbanismo, projeto de interiores, } \\
\text { desenho e meios de representação gráfica e } \\
\text { informática aplicada à arquitetura e urbanismo }\end{array}$ \\
\hline $\begin{array}{l}\text { A habilidade na elaboração e instrumental na feitura e interpretação de } \\
\text { levantamentos topográficos, com a utilização de aerofotogrametria, } \\
\text { fotointerpretação e sensoriamento remoto, necessários na realização de } \\
\text { projetos de arquitetura, urbanismo e paisagismo e no planejamento } \\
\text { regional }\end{array}$ & $\begin{array}{l}\text { Informática aplicada à arquitetura e urbanismo, } \\
\text { topografia e tecnologia da construção }\end{array}$ \\
\hline
\end{tabular}

Fonte: BRASIL, (2010a), e BRASIL, (2010b), elaborado pelas autoras

A partir do explicitado no quadro anterior, é possível perceber que apenas três competência preconizada pelas DCNs não são complementadas a partir da integração de conteúdos utilizando a ferramenta BIM, que são: conhecimento dos aspectos antropológicos, sociológicos e econômicos relevantes em todo o espectro de necessidades, aspirações e expectativas individuais e coletivas quanto ao ambiente construído; os conhecimentos de estética e história das artes; e teoria e história da arquitetura, urbanismo e paisagismo. Neste caso, apesar de ser possível a discussão destes aspectos em várias áreas do conhecimento, não se considera a ferramenta BIM como facilitador da integração dos mesmos.

Com base na interpretação do Quadro 2, para mostrar a efetivação desta compatibilização aplicada, será discutida a aplicação da tecnologia BIM no curso de arquitetura e urbanismo, o qual tem obtido resultados de integração, a partir do uso da ferramenta e da estruturação interna da matriz curricular.

\section{Discussão: Aplicação no ensino de arquitetura e urbanismo}

Succar (2009), faz uma investigação sistemática sobre os divergentes campos da tecnologia BIM, desenhando um cenário e identificando suas partes conceituais e estado da arte. No que tange às partes que estavam sendo estudadas e desenvolvidas, o autor estruturou os campos da tecnologia BIM entre: tecnologia, processo e políticas.

A partir do exposto por Succar (2009), compreende-se que o campo do processo é uma ordenação específica de atividades de trabalho em tempo e lugar, com começo e fim, entradas e saídas, claramente identificadas em uma estrutura para a ação, ou seja, o processo de projeto. Neste campo, o autor identificou a maturidade do processo e a classificou em três estágios.

0 estágio 1 refere-se à modelagem baseada em objetos. Em que a implementação da tecnologia BIM é iniciada e desenvolvida por um software paramétrico tridimensional baseado em objeto, como por exemplo, ArchiCAD ${ }^{\circledR}$, Revit ${ }^{\circledR}$, Digital Project ${ }^{\circledR}$ e Tekla ${ }^{\circledR}$. Neste estágio, o projetista modela o objeto e gera os documentos, em uma única disciplina dentro do projeto, da construção ou da operação, conseguindo avanços somente na mudança para uma projetação em três dimensões e gerando documentos de documentação e visualização em duas dimensões. As práticas colaborativas neste estágio não são significantes em níveis interdisciplinares, no entanto, a natureza detalhada dos modelos incentiva o rápido rastreamento das fases do ciclo de vida do projeto, demonstrando assim, ao término deste estágio, os benefícios potenciais de desenvolver projetos com outros colaboradores. 
O estágio 2 engloba a colaboração baseada em modelos. É executada com colaboradores multidisciplinares e cada componente pode ser responsável por uma competência do projeto.

O estágio 3 abrange a integração baseada em redes. Os modelos tornam-se integrados e interdisciplinares, permitindo análises complexas em estágios iniciais de projeto e construção virtuais. Os entregáveis do modelo vão além das propriedades semânticas do objeto, incluindo business intelligence, princípios de construção enxuta, políticas verdes e custeio total do ciclo de vida, a partir do trabalho colaborativo.

A partir das definições de Succar (2009) é válido refletir sobre a interdisciplinaridade exigida à formação do arquiteto e urbanista e repensar as habilidades que podem ser transmitidas no estágio 1. Este estágio, onde é possível averiguar as possibilidades de parametrização, a projetação em três dimensões e a simulação de funcionamento e construção edilícia, pode ser interdisciplinar, desde que o acadêmico tenha conhecimento para ambos. Não necessariamente precisa haver trabalhos colaborativos para a construção do conhecimento abranger mais de uma competência.

O processo projetual, permitido pelas ferramentas BIM também propicia a reunião de disciplinas distintas e sua maior interatividade. A sequência de decisões tomadas e retroalimentadas no projeto reafirma a interdisciplinaridade que pode ser obtida.

A matriz curricular em questão, foi pensada a partir da busca pela interdisciplinaridade com base no uso da ferramenta e sob a ótica das competências a serem alcançadas nesse processo. Desse modo, o uso do BIM se dá desde o primeiro ano, ainda que focado na estrutura básica do estágio 1. No entanto, este estágio é aplicado ao longo da matriz, de forma diferenciada e interdisciplinar, aprimorando a ideia de Succar (2009).

Na Figura 2, observam-se os conteúdos das DCNs mais explorados em cada ano de formação da matriz curricular, assim como a relação das respostas esperadas pela aplicação do BIM, visto sua aplicação no Estágio 1, e a preparação e maturação para o Estágio 2, no campo profissional.

O primeiro ciclo de aplicação iniciou-se em 2014-1 e, portanto, a matriz se encontra, na corrente data, em fase de conclusão de sua primeira turma. Nesse momento é possível compreender os aspectos positivos e negativos da implementação, como forma de elucidar a experiência de ensino obtida.

Neste contexto, alguns momentos da matriz curricular são de extrema importância para o sucesso do processo de aprendizagem e apreensão das competências. Já no primeiro semestre o acadêmico tem contato com as ferramentas BIM nos componentes curriculares: Projeto Arquitetônico: Processos Criativos e Desenho Arquitetônico I. No segundo semestre os componentes curriculares que utilizam a tecnologia BIM são: Projeto Arquitetônico: Plástico Formal; Desenho Arquitetônico II e Estudo do Terreno.

Neste primeiro ano, o acadêmico inicia o contato com o software BIM, aprendendo não somente a desenhar tecnicamente, mas a fazer as composições de materiais construtivos, pensando e refletindo sobre acabamentos e elementos de composição edilícia, tanto nos componentes de Desenho Arquitetônico, quanto nos de Projeto Arquitetônico. Isto porque aplicam os conhecimentos adquiridos nos demais componentes curriculares que contemplam estes dois primeiros semestres, como habitabilidade que dá a base do conforto ambiental, geometria, e componentes de fundamentação como arquitetura, urbanismo e paisagismo: introdução e história; e fundamentos da composição da paisagem, estes dois últimos, dependendo mais das reflexões encaminhadas pelo corpo docente. 
BAtistello, Paula; BALZAN, Katiane Laura; PEReirA, Alice Theresinha Cybis.

BIM no ensino das competências em arquitetura e urbanismo: transformação curricular

Figura 2 - Aplicações do BIM durante o processo de formação do arquiteto e urbanista

\section{APLICACÕES DO BIM}

DURANTE O PROCESSO DE FORMAÇÃO DO ARQUITETO E URBANISTA

RESPOSTAS DO BIM

Modelagem do objeto Projetação em 3D Documentação

Modelagem do objeto Projetação em 3D Simulação Documentação

Modelagem do objeto Projetação em 3D Simulação Documentação

Modelagem do objeto

Projetação em 3D Simulação Documentação

Prática Colaborativa Interdisciplinar

Modelagem do objeto Projetação em 3D Simulação Documentação Prática Colaborativa Interdisciplinar

\section{ANO}

Desenho e Meios de Expressão Gráfica

Informática Aplicada à Arquitetura e

Urbanismo

Projeto de Arquitetura

Conforto Ambiental

- Topografia

$$
29 \text { ANO }
$$

Projeto de Arquitetura

Informática Aplicada à Arquitetura e

Urbanismo

Projeto de Urbanismo

Projeto de Paisagismo

Projeto de Interiores

- Desenho e Meios de Expressão Gráfica

$$
\text { 3ANO }
$$

Projeto de Arquitetura

Projeto de Urbanismo

Conforto Ambiental

Topografia

\section{$4^{0}$ ANO}

Projeto de Arquitetura

Projeto de Interiores

Técnicas Retrospectivas

Sistemas Estruturais

Conforto Ambiental

Tecnologia da Construção

\section{$5^{0}$ ANO}

Projeto de Arquitetura

Projeto de Urbanismo

Trabalho de Conclusão de Curso

VIDA

PROFISSIONAL 
A tecnologia BIM intercede como uma ferramenta de efetivação de competências, uma vez que possibilita ao estudante refletir sobre o terreno o qual está aprendendo a manipular nas disciplinas. Nestas, o aluno obtém: os conceitos de proporções e volumetrias, que são trabalhados no desenho arquitetônico; conhecimento da relação topográfica, altimétrica e planimétrica, aplicada na disciplina de Estudo do Terreno; e finalmente, nas disciplinas projetuais, quando pensa nos objetos que projeta e suas soluções espaciais e construtivas.

Neste primeiro ano, o acadêmico aprende a projetar em 3D, utilizando o processo de projeto mais alinhado com o BIM na linha projetual, quando modela o objeto, gera documentação para impressão e visualizações em duas dimensões. É válido ressaltar que os projetos gerados neste primeiro ano, são para apropriações espaciais, soluções modulares e de mobiliários, cujos resultados o acadêmico produz modelos em escala 1:1 com o apoio do laboratório Pronto 3D ${ }^{(2)}$ Chapecó ou outras formas de execução que pretenda usar. Isso comprova que a geração da documentação é validada já neste primeiro ano, pois os projetos são exequíveis, todos são executados pelos acadêmicos e com a ajuda de terceiros e dispostos pelo Campus da Unochapecó como forma de validar o projeto a partir da reflexão dos acadêmicos sobre os usos e a verdadeira aplicação de suas intenções projetuais.

Nos segundo e terceiro ano é possível aprofundar a interdisciplinaridade, uma vez que o acadêmico já domina as ferramentas básicas de modelagem necessárias e já evolui em relação à apreensão de algumas competências de sua formação. Nesse momento, há integração de conteúdos disciplinares previstos na própria matriz, onde os ementários dos componentes estão diretamente ligados e a integração dos mesmos previstas, de forma que vários componentes só podem ser cursados ao mesmo tempo pelos estudantes, intitulado pela Unochapecó como "co-requisito".

Os componentes curriculares que possuem a interdisciplinaridade previstas em ementários a partir da matriz em discussão, distribuídos por semestres, são os que seguem: i) terceiro semestre - Arquitetura Paisagística, Projeto Arquitetônico: Residência Unifamiliar e Arquitetura de Interiores I; ii) quarto semestre - Desenho Urbano, Projeto Arquitetônico: Institucional, e Conforto Ambiental: Térmico; iii) quinto semestre - Projeto Integrado: Habitação Social (que já integra projetos arquitetônico e urbanístico no mesmo componente) e reúne conhecimentos de Sistemas Estruturais e Materiais: Construtibilidade e Interfaces; iv) sexto semestre - Projeto Arquitetônico: Grandes Vãos, Estruturas de Aço, Conforto Ambiental: Acústico e conhecimentos de Tecnologia da Construção e Instalações Prediais: Hidrossanitária I.

Os resultados da aplicação da tecnologia BIM, no segundo e terceiro anos, ainda são apresentados como no primeiro ano, com modelagem do objeto e projetação tridimensional, e documentação. No entanto, a interdisciplinaridade prevista nos componentes curriculares é possível e facilitada pelo uso da ferramenta. Os alunos trabalham os conteúdos, de cada componente, aplicados aos demais e evoluem os projetos com estes conhecimentos integrados.

No quarto ano de formação há uma compilação de todo esse conhecimento obtido e a real efetivação da aplicação da ferramenta, a partir do componente de Coordenação de Projetos, que por sua vez, integra o conteúdo de Projeto Arquitetônico: Verticalidade, Concreto Armado I, Instalações Prediais: Elétrica e Instalações Prediais: Hidrossanitária II. É um importante momento de interdisciplinaridade aplicada em um componente curricular, quando o acadêmico percebe que está apto a integrar conhecimentos diversos em um mesmo projeto. As habilidades de análise e proposição estrutural, de construção por sua simulação, e de projetar são reforçadas neste momento. Além disto, 
este aluno se prepara para a migração para o estágio 2, momento em que é perceptível a necessidade da equipe multidisciplinar para a futura atuação profissional. Neste momento há uma efetivação de competências profissionais, que são facilitadas pela ferramenta e pelo processo de projetar permitido pela tecnologia BIM. No oitavo semestre e para findar o $4^{\circ}$ ano, o acadêmico integra conhecimentos em Técnicas Retrospectivas, Projeto Arquitetônico: Complexidade, Conforto Ambiental: Lumínico e Arquitetura de Interiores II, da mesma forma que nos anos anteriores, mas com maturidade reflexiva projetual e com maior aporte teórico. Neste ano, o acadêmico já faz simulações com segurança e consegue tomar decisões mais acertadas no processo projetual.

Desse modo, no quinto ano o acadêmico caminha para a autonomia profissional, encontrando os últimos momentos de desenvolvimento de projeto em equipes e integração de disciplinas curriculares. $\mathrm{Na}$ última fase, especificamente, o desenvolvimento do trabalho de conclusão de curso é individual, o que também demonstra o alcance da interdisciplinaridade e resultados de uma matriz que foi formulada a partir dos resultados que o BIM pode efetivar. Assim, os trabalhos de conclusão de curso do curso têm mostrado diversidade de soluções, graficações realísticas e soluções construtivas em bons níveis de detalhes, variadas imagens explicativas e simulações, sejam de modificação do espaço, sejam de conforto ambiental, vídeos ilustrativos e de funcionamentos. Além da representação gráfica, todas as documentações relevantes e necessárias para a apresentação de um projeto de conclusão de curso são também produzidas e apresentadas.

\section{Considerações Finais}

As ferramentas BIM ainda estão em processo de pesquisa e desenvolvimento, no que diz respeito às áreas e conteúdos complementares em relação ao processo de projeto arquitetônico.

O estágio 1 do BIM (SUCCAR, 2009), é atingido na matriz analisada, especialmente por três fatores: a previsão de integração dos conhecimentos na própria matriz, trabalhando várias disciplinas como co-requisito; pelo envolvimento e esforço dos docentes do mesmo semestre em trabalhar temas comuns; e, especialmente, pelo fato dos acadêmicos já estarem habituados a trabalhar com BIM desde o primeiro semestre. Iniciar o processo de desenho, expressão gráfica e informática aplicada à arquitetura e ao urbanismo, utilizando a metodologia de projetação do produto em três dimensões com opções parametrizadas, faz com que o acadêmico eduque seu pensamento projetual, entendendo suas decisões e suas consequências destas rapidamente. Assim, a ferramenta torna-se um facilitador da interdisciplinaridade.

A partir da transformação curricular analisada, são elencados aspectos bastante positivos de implementação do BIM no ensino de arquitetura e urbanismo. O potencial de visualização do todo por parte do acadêmico a partir das visualizações em 3D, mesmo nas fases iniciais de sua formação é ampliado, assim como sua capacidade de detalhamento e compreensão dos elementos construtivos. Isso aproxima o exercício acadêmico da realidade e aumenta o controle do aluno no decorrer da sequência de tomada de decisões do projeto. Além disso, uma característica bastante importante das atividades desenvolvidas é o trabalho colaborativo entre equipes, em grande parte dos componentes que trabalham o conteúdo de projeto de arquitetura, de interiores, de paisagismo e de urbanismo. Vários projetos são formulados em grupos pequenos e médios, para que a ação de colaborar seja capacitada. Esse aspecto aproxima mais uma vez o acadêmico da futura realidade profissional, ao mesmo tempo que permite o amadurecimento da ação de colaboração. Nesse processo, o uso do BIM facilita o 
desenvolvimento dos projetos, assim como permite avanços em relação a outros processos de projeto já utilizados em matrizes curriculares anteriores, no mesmo curso.

Em contrapartida, alguns obstáculos são encontrados ao longo da execução da matriz. Um deles é a falta de domínio da tecnologia BIM e as ferramentas que a compõe, por parte de professores que trabalham conteúdos do núcleo de conhecimentos profissionais. Em um cenário em que a ferramenta sugere mudança no processo de projeto, o domínio da mesma por parte do docente tem se mostrado fator diferencial para maior aproveitamento do componente curricular. Percebe-se também maior engajamento e aproximação em relação aos novos métodos e processos em algumas linhas em específico, a citar, projeto de arquitetura, de interiores, e conforto ambiental, em detrimento de outras, de urbanismo, especialmente nas escalas de planejamento urbano e regional. Isso posto, percebe-se certa dificuldade e menor autonomia do acadêmico, ao final do curso, para trabalhar com escalas maiores de projeto - projeto urbano e planejamento urbano e regional, embora domine muito a escala do detalhe. Neste sentido, destaca-se aqui a necessidade de revisão da inserção dos componentes curriculares que trabalham especificamente estes conteúdos no processo de projeto a partir do City Information Modeling (CIM), para conseguir alinhar o processo de projeto nas duas macroáreas do conhecimento.

A falta de interoperabilidade entre softwares e da atualização docente dificulta o aproveitamento da tecnologia BIM no processo de ensino-aprendizagem, especialmente para alcançar com plenitude o estágio 2, ou ainda, avançar para o estágio 3. Para isso, é necessário repensar o formato dos últimos dois anos de formação da matriz curricular em questão e a união de esforços com cursos de conhecimentos correlatos à arquitetura e urbanismo, efetivando assim um trabalho colaborativo e em equipe. Matrizes compartilhadas entre cursos como Engenharia Civil, Técnico em Edificações, Engenharia Elétrica, Engenharia Mecânica e Mecatrônica, Eletrotécnica, Engenharia Agronômica entre outros, podem possibilitar o trabalho interdisciplinar e em rede.

Isto pode ocorrer a partir do envolvimento de cursos com conhecimentos complementares à formação do arquiteto e urbanista durante a graduação, indicando que futuros profissionais já iniciem um compartilhamento de informações, uma estruturação de projetos colaborativos e, especialmente, a prática do uso do BIM para iniciar a vida profissional com outra visão, preparado para um mercado profissional que espera a aplicação das competências que lhe cabe.

\section{Notas}

(1) Resolução No 2/2010 institui as DCN's do curso de graduação em Arquitetura e Urbanismo, em seu Art. $4^{\circ}$ diz que: "O curso de Arquitetura e Urbanismo deverá ensejar condições para que o futuro egresso tenha como perfil: I - sólida formação de profissional generalista;[...]".

(2) Laboratório de Prototipagem e Novas Tecnologias orientadas ao 3D - FABLAB -consiste em um espaço de ensino, pesquisa e extensão na área de materialização da forma por meio de técnicas automatizadas.

\section{Referências}

ANDRADE, M. L. V. X. D.; RUSCHEL, R. C.; MOREIRA, D. D. C. O processo e os métodos. In: KOWALTOWSKI, D. C. C. K., et al. $O$ processo de projeto em arquitetura: da teoria à tecnologia. Campinas: Oficina de Textos, 2011. Cap. 4, p. $80-100$.

ASIMOW, M. Introdução ao projeto de engenharia. Tradução de José Walderley Coêlho Dias. São Paulo: Mestre JOU, 1968. $171 \mathrm{p}$. 
AZHAR, S.; KHALFAN M.; MAQSOOD, T. Building information modeling (BIM): now and beyond. Australasian Journal of Construction Economics and Building, 2012, p. 15-28. Disponível em: http://epress.lib.uts.edu.au/journals/index.php/AJCEB/article/download/3032/3245. Acesso em 26 de outubro de 2018.

BATISTELLO, P. Saberes interdisciplinares em arquitetura e urbanismo: um modelo gamificado como incentivador do processo projetual. 2018. 353 p. Tese (Doutorado) - Universidade Federal de Santa Catarina, Centro Tecnológico, Programa de Pós-Graduação em Arquitetura e Urbanismo, Florianópolis, 2018. Disponível em: http://www.bu.ufsc.br/teses/PARQ0308-T.pdf. Acesso em 19 mar. 2019.

BRASIL. Lei 12.378, de 31 de Dezembro de 2010. Regula o exercício das profissões de Engenheiro, Arquiteto e Engenheiro-Agrônomo, e dá outras providências. Diário Oficial da República do Brasil. Casa Civil. Brasília, DF, 24 dez. 1966.

BRASIL. Câmara de Educação Superior. Resolução nº 02 de 17 de Junho de 2010. Diretrizes Curriculares Nacionais do curso de graduação em Arquitetura e Urbanismo. Diário Oficial da República do Brasil. Ministério da Educação. Conselho Nacional da Educação. Brasília, DF, 18 jun. 2010. Seção 1, p. 37-38.

BROADBENT, G. Metodología del diseño arquitetctónico. In: BROADBENT, G.; WARD, A. Metodologia del diseño arquitectonico. Tradução de Ana PERSOFF; Jorge PLANAS, et al. Barcelona: Gustavo Gili, 1971. p. 21 -35.

CAMPOS NETTO, C. Autodesk Revit Architecture 2016: conceitos e aplicações. 1.ed. São Paulo: Érica, 2016.

CHECCUCCI, Érica de Sousa; AMORIM, Arivaldo Leão de. Método para análise de componentes curriculares: identificando interfaces entre um curso de graduação e BIM PARC Pesquisa em Arquitetura e Construção, Campinas, SP, v. 5, n. 1, p. 6-17, jun. 2014. ISSN 1980-6809. Disponível em: <https://periodicos.sbu.unicamp.br/ojs/index.php/parc/article/view/8634540>. Acesso em: 09 abr. 2019. DOI:https://doi.org/10.20396/parc.v5i1.8634540.

COTTA, M. M.; COSTA, D. D.; MENDONÇA, E. T. Portfólio reflexivo: uma proposta de ensino e aprendizagem orientada por competências. Ciência \& Saúde Coletiva, v. 18, n. 6, p. 1847 - 1856, 2013. DOI:http://dx.doi.org/10.1590/S1413-81232013000600035.

DELATORRE, V. Potencialidades e limites do BIM no ensino de arquitetura: uma proposta de implementação. 2014. 293p. Dissertação (Mestrado em Arquitetura) - Programa de pós-graduação em Arquitetura, Universidade Federal de Santa Catarina, Florianópolis, 2014.

EASTMAN, C.; TELCHOLZ, P.; SACKS R.; LISTON, K. Manual de BIM: um guia de modelagem da informação da construção para arquitetos, engenheiros, gerentes, construtores e incorporadores. Porto Alegre: Bookman, 2014.

INEP - INSTITUTO NACIONAL DE ESTUDOS E PESQUISAS EDUCACIONAIS ANÍSIO TEIXEIRA; CONFEA - CONSELHO FEDERAL DE ENGENHARIA, ARQUITETURA E AGRONOMIA. Trajetória e estado da arte da formação em engenharia, arquitetura e agronomia. Brasília: INEP; CONFEA, 2010.

JONES, J. C. Métodos de diseño. Tradução de María Luisa López Sardá. Barcelona: Gustavo Gili, 1976. 370 p.

LAWSON, B. Como arquitetos e designers pensam. Tradução de Maria Beatriz MEDINA. São Paulo: Oficina de Textos, 2011.

LEE, G.; SACKS, R.; EASTMAN, C. M. Specifying Parametric Building Project Behavior (Bob) for a Building Information Modeling System. Automation in Construction, v. 15, p. 758-776, 2006. Disponível em:

https://yonsei.pure.elsevier.com/en/publications/specifying-parametric-building-object-behavior-bob-for-a-building. Acesso em 05 de Novembro de 2018.

MARKUS, T. A. El dimensionado y la valoración del proceso de ejecución de un edificio como método de diseño. In: BROADBENT, G.; WARD, A. Metodologia del diseño arquitectonico. Tradução de Ana PERSOFF; Jorge PLANAS, et al. Barcelona: Gustavo Gilli, 1971. P. 231-256. 
BAtistello, Paula; BALZAN, Katiane Laura; PEReirA, Alice Theresinha Cybis.

BIM no ensino das competências em arquitetura e urbanismo: transformação curricular

SUCCAR, B. Building Information Modelling Framework: a research and delivery foundation for industry stakeholders. Automation in Construction, v. 18, p. 357 - 375, mai. 2009.

DOI:https://doi.org/10.1016/j.autcon.2008.10.003

RUSCHEL, R. C.; ANDRADE, M. L. V. X. de; MORAIS, M. de O ensino do BIM no Brasil: onde estamos? Ambiente Construído, v. 13, n. 2, p. 151 - 165. Porto Alegre, abr/jun 2013. Disponível em https://seer.ufrgs.br/ambienteconstruido/article/view/36881/25905. Acesso em o9 de abr. 2019. DOI:http://dx.doi.org/10.1590/S1678-86212013000200012

VAN DER KLINK, M.; BOON, J.; SCHLUSMANS, K. Competências e ensino superior profissional: presente e futuro. Revista Europeia de Formação Profissional, v. 40, n. 1, p. 72 - 89, 2007.

VAN DER KLINK, M. R.; BOON, J. Competencies: the triumph of a fuzzy concept. International Journal of Human Resources Development and Management (IJHRDM), v. 3, n. 2, p. 125 - 138, 2003. Disponível em: https://www.inderscience.com/info/inarticle.php?artid=2415. Acesso em 18 mar. 2018.

\section{${ }_{1}^{1}$ Paula Batistello}

Arquiteta e Urbanista. Doutora. Docente no curso de Arquitetura e Urbanismo e Diretora de Logística, Projetos e Obras da Universidade Comunitária da Região de Chapecó. Endereço postal: Servidão Anjo da Guarda, 295,

Chapecó, SC, Brasil, 89809-900

\section{${ }^{2}$ Katiane Laura Balzan}

Arquiteta e Urbanista. Doutoranda em Arquitetura e Urbanismo. Docente e Coordenadora do curso de Arquitetura e Urbanismo da Universidade Comunitária da Região de Chapecó. Endereço postal: Servidão Anjo da Guarda, 295, Chapecó, SC, Brasil, 89809-900

\section{Alice Theresinha Cybis Pereira}

Arquiteta e Urabnista. PhD. Docente Titular Aposentada Voluntária. Endereço postal: Rua Eng. Agronômico Andrei Cristian Ferreira, s/n, Trindade, Florianópolis, SC, Brasil, 88040-900 